\title{
Spatial-temporal characteristics of drought detected from meteorological data with high resolution in Shaanxi Province, China
}

\author{
WANG Yudan $^{1,2,3}$, KONG Yunfeng $^{1,2 *}$, CHEN Hao ${ }^{3}$, DING Yongjian ${ }^{4}$ \\ ${ }^{1}$ College of Environment and Planning, Henan University, Kaifeng 475004, China; \\ ${ }^{2}$ Key Laboratory of Geospatial Technology for the Middle and Lower Yellow River Regions, Ministry of Education, Henan \\ University, Kaifeng 475004, China; \\ ${ }^{3}$ School of Geography and Environment, Baoji University of Arts and Sciences, Baoji 721013, China; \\ ${ }^{4}$ Northwest Institute of Eco-Environment and Resources, Chinese Academy of Sciences, Lanzhou 730000, China
}

\begin{abstract}
The spatial pattern of meteorological factors cannot be accurately simulated by using observations from meteorological stations (OMS) that are distributed sparsely in complex terrain. It is expected that the spatial-temporal characteristics of drought in regions with complex terrain can be better represented by meteorological data with the high spatial-temporal resolution and accuracy. In this study, Standard Precipitation Evapotranspiration Index (SPEI) calculated with meteorological factors extracted from ITPCAS (China Meteorological Forcing Dataset produced by the Institute of Tibetan Plateau Research, Chinese Academy of Sciences) was applied to identify the spatial-temporal characteristics of drought in Shaanxi Province of China, during the period of 1979-2016. Drought areas detected by SPEI calculated with data from ITPCAS (SPEI-ITPCAS) on the seasonal scale were validated by historical drought records from the Chinese Meteorological Disaster Canon-Shaanxi, and compared with drought areas detected by SPEI calculated with data from OMS (SPEI-OMS). Drought intensity, trend and temporal ranges for mutations of SPEI-ITPCAS were analyzed by using the cumulative drought intensity (CDI) index and the Mann-Kendall test. The results indicated that drought areas detected from SPEI-ITPCAS were closer to the historical drought records than those detected from SPEI-OMS. Severe and exceptional drought events with SPEI-ITPCAS lower than -1.0 occurred most frequently in summer, followed by spring. There was a general drying trend in spring and summer in Shaanxi Province and a significant wetting trend in autumn and winter in northern Shaanxi Province. On seasonal and annual scales, the regional and temporal ranges for mutations of SPEI-ITPCAS were different and most mutations occurred before the year 1990 in most regions of Shaanxi Province. The results reflect the response of different regions of Shaanxi Province to climate change, which will help to manage regional water resources.
\end{abstract}

Keywords: SPEI; drought areas; meteorological data; cumulative drought intensity; drying trend; wetting trend

Citation: WANG Yudan, KONG Yunfeng, CHEN Hao, DING Yongjian. 2020. Spatial-temporal characteristics of drought detected from meteorological data with high resolution in Shaanxi Province, China. Journal of Arid Land, 12(4): 561-579. https://doi.org/10.1007/s40333-020-0066-x

\section{Introduction}

Drought is a damaging and frequent natural disaster (He et al., 2011) that is significantly related to temperature abnormalities and shortage of precipitation (Salehnia et al., 2017a). It is sensitive to

\footnotetext{
*Corresponding author: KONG Yunfeng (E-mail: yfkong@henu.edu.cn)

Received 2019-07-03; revised 2020-01-12; accepted 2020-02-11

(C) Xinjiang Institute of Ecology and Geography, Chinese Academy of Sciences, Science Press and Springer-Verlag GmbH Germany, part of Springer Nature 2020
} 
climate change (Kogan et al., 2013; Jia et al., 2016) and has a significant impact on economic, ecological and agricultural activities. Research on the spatial-temporal characteristics of drought will help to identify the correlation of drought with meteorological, hydrological and ecological processes (Yu et al., 2015; Yuan et al., 2015), and to further evaluate the impact of climate change on human society.

Currently, research on the spatial-temporal characteristics of regional drought faces the following challenges: (1) the applicability of drought indices varies greatly due to the specific climatic features of the study area (Qiao et al., 2012; Yang et al., 2017); (2) the accuracy of drought monitoring depends heavily on the accuracy and spatial-temporal resolution of the input data for the drought index (Liu et al., 2016; Wang et al., 2016; Salehnia et al., 2017b); and (3) the occurrence and spatial-temporal distribution of drought events identified by the drought index need validation (Liu et al., 2018; Wang et al., 2018). It is imperative to find an appropriate drought index, a reliable validation method and the meteorological data with high spatial-temporal resolution to improve the quality of drought monitoring over specific regions.

Meteorological drought is generally monitored and measured by multifactorial drought indices involving water and energy balance (Vasiliades and Loukas, 2009; Dai, 2011; Paulo et al., 2012; Gobena and Gan, 2013), such as the Palmer Drought Severity Index (PDSI), Self-calibrated PDSI (Sc-PDSI) (Wells et al., 2004), and Standard Precipitation Evapotranspiration Index (SPEI) (Vicente-Serrano et al., 2010a). PDSI requires parameters including soil water holding capacity, groundwater level and lake/reservoir level (Ma et al., 2015), which are not available in many circumstances. Furthermore, the temporal scale of PDSI is fixed (Vicente-Serrano et al., 2011), although drought is a multi-scale phenomenon (Changnon and Easterling, 1989; Pandey and Rafmasastri, 2010). Sc-PDSI is an improved version of PDSI (Wells et al., 2004; Liu et al., 2015), but the temporal scale is still not alterable. In contrast, SPEI combines the sensitivity of PDSI to evaporation changes and the multi-temporal nature of the Standardized Precipitation Index (SPI) (Vicente-Serrano et al., 2010a). Besides, it needs fewer parameters compared with PDSI when the Thornthwaite (Th) method is used to calculate evaporation. Thus, SPEI has been widely used to elaborate the spatial-temporal characteristics of regional drought and to reconstruct the spatialtemporal distribution of drought (Allen et al., 2011; Meza, 2013).

Much research on drought quantification, monitoring and analysis has been conducted by machine learning models or spatial interpolation methods with metrological factors extracted from observations from meteorological stations (OMS) (Jiang et al., 2015; Rhee and Im, 2017; Wang et al., 2019; Zhang et al., 2019). However, the spatial interpolation of metrological factors (e.g., precipitation) brings significant errors due to the sparse observations and the complex terrain. Accuracy of SPEI forecasting by machine learning models with multisource data needs further theoretical investigation, particularly because SPEI may vary under different climatic conditions (Rhee and Im, 2017). It is more reliable to adopt meteorological datasets with high spatial-temporal resolution to directly quantify the drought based on drought indices (Vicente-Serrano et al., 2010b; Hannaford et al., 2011; Wang et al., 2016). Many studies have tested the applicability of various meteorological datasets in drought analysis at multiple scales under different climatic conditions. For example, Salehnia et al. (2017b) calculated eight drought indices with AgMERRA (Agricultural Model Intercomparison and Improvement Project based on the NASA Modern-Era Retrospective Analysis for Research and Applications) precipitation data and OMS data for drought monitoring. Results showed that the correlation between drought events and the former was higher than that between drought events and the latter. Naumann et al. (2014) investigated five different datasets and three drought indicators with regard to their capability to improve drought monitoring in Africa. They found that the extents of drought areas identified by drought indicators were different. Spinoni et al. (2019) constructed a dataset of meteorological drought events from 1951 to 2016 based on Global Precipitation Climatology Centre (GPCC) and Climatic Research Unit (CRU) time-series datasets with a spatial resolution of $0.5^{\circ}$. It can be concluded that the spatial resolution and accuracy of the gridded meteorological data and a suitable drought index were essential to identify the occurrence, intensity and spatial extent of drought.

Multiple metrics (e.g., duration, intensity and area) of drought events were extracted from 
historical drought records and served as "ground truth" to validate the estimates obtained from drought indices (Spinoni et al., 2019; Wang et al., 2019). Drought detected from data with the high spatial resolution and accuracy can be better validated by drought records. In addition, meteorological data with a long temporal range can help to depict the trend of drought. The temporal range (1979-2016) and spatial resolution (approximately $10 \mathrm{~km} \times 10 \mathrm{~km}$ ) of ITPCAS (China Meteorological Forcing Dataset produced by the Institute of Tibetan Plateau Research, Chinese Academy of Sciences) (Chen et al., 2011) can better meet those requirements of drought analysis compared with other commonly used meteorological products such as TRMM (Tropical Rainfall Measuring Mission) $\left(0.25^{\circ} \times 0.25^{\circ}\right)$ and CMORPH (Climate Prediction Center Morphing Technique) (starting from 1998). Numerous studies have demonstrated the efficiency of ITPCAS in hydrological and meteorological applications across China (Guo and Wang, 2013; Xue et al., 2013; Wang et al., 2018).

In this study, the spatial-temporal characteristics of drought in Shaanxi Province of China were reconstructed by SPEI and ITPCAS data, and validated by historical drought records. Firstly, the SPEI of all grids with the spatial resolution of $10 \mathrm{~km} \times 10 \mathrm{~km}$ in Shaanxi Province was calculated with the temperature and precipitation data of ITPCAS (termed as SPEI-ITPCAS) from 1979 to 2016. Then, drought areas detected from SPEI-ITPCAS were validated by drought records extracted from the Chinese Meteorological Disaster Canon-Shaanxi, and compared with those calculated by OMS and ordinary Kriging interpolation (OKI). Finally, drought intensity, trends and mutations of SPEI-ITPCAS in Shaanxi Province from 1979 to 2016 were analyzed using the cumulative drought intensity (CDI) index and the Mann-Kendall (MK) test. This study aims to give more details about the spatial-temporal characteristics of drought in Shaanxi Province, especially in those ungauged areas which were neglected or poorly represented in previous studies (Jiang et al., 2015; Wang et al., 2019; Zhang et al., 2019).

\section{Study area and methods}

\subsection{Study area}

Shaanxi Province is located on the boundary between the western arid zone and the eastern monsoon zone of China $\left(31^{\circ} 42^{\prime}-39^{\circ} 35^{\prime} \mathrm{N}, 105^{\circ} 29^{\prime}-111^{\circ} 15^{\prime} \mathrm{E}\right.$; Fig. 1). Meteorological disaster, especially drought, frequently occurs with damaging effects on the ecological system and regional economy. Shaanxi Province can be divided into three regions with regard to geography and climate: the northern Loess Plateau with a cold, arid climate; the middle Guanzhong Plain with a mild climate; and the southern Qinba Mountainous region with a warm, wet climate (Liu et al., 2013). Qinling Mountains run across the middle of Shaanxi Province with significant climate discrepancy between the northern and southern sides of the mountains. The Loess Plateau in the northern part of Shaanxi Province (briefly, northern Shaanxi) has a sub-arid monsoon climate with average annual precipitation varying greatly from 300 to $600 \mathrm{~mm}$. It is prone to both droughts and waterlogging. The Guanzhong Plain in the middle of Shaanxi Province (briefly, Guanzhong) has a warm sub-humid monsoon climate with average annual precipitation between 550 and $700 \mathrm{~mm}$. The Qinba Mountainous region in the southern part of Shaanxi Province (briefly, southern Shaanxi) has a subtropical humid monsoon climate with average annual precipitation between 800 and 1300 $\mathrm{mm}$. Flash floods and geological disasters occur frequently in this southern region. The annual mean temperature of the entire Shaanxi Province is about $13^{\circ} \mathrm{C}$, with regional means of $10^{\circ} \mathrm{C}$ in the north, $13^{\circ} \mathrm{C}$ in the middle and $15^{\circ} \mathrm{C}$ in the south (Wan et al., 2013). For administrative purposes, Shaanxi Province is divided into ten areas of prefecture-level city (APC). Yulin and Yan'an belong to northern Shaanxi; Baoji, Xianyang, Tongchuan, Weinan and Xi'an belong to Guanzhong; and Shangluo, Ankang and Hanzhong belong to southern Shaanxi (Fig. 1).

\subsection{Data sources}

Temperature and precipitation data (1979-2016) with the horizontal spatial resolution of $0.1^{\circ}$ 


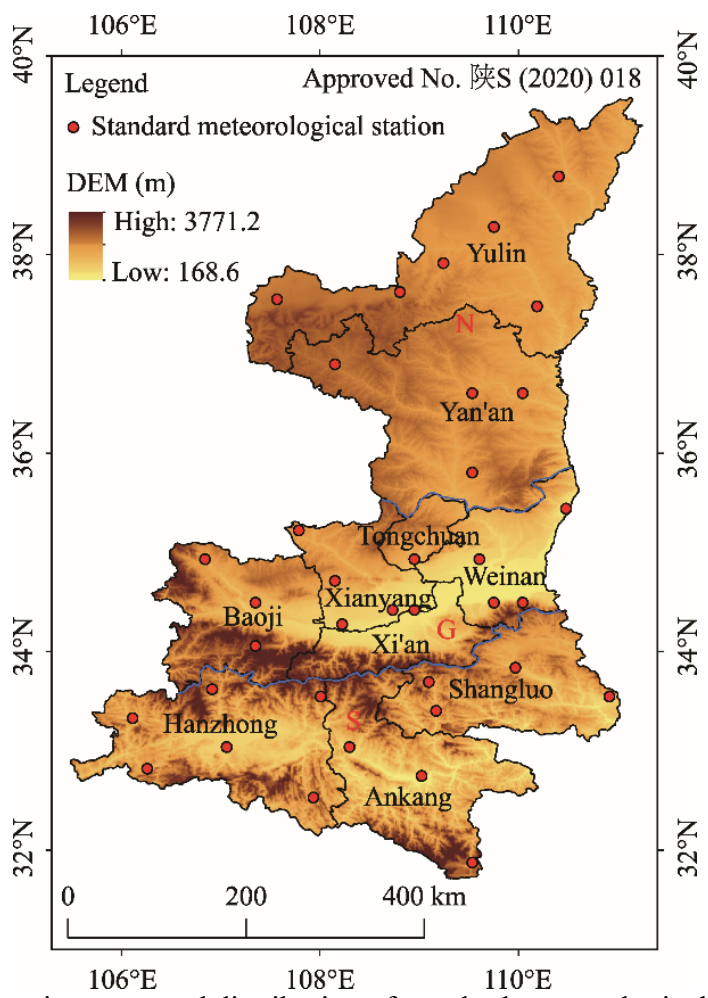

Fig. 1 Topography, administrative areas and distribution of standard meteorological stations of Shaanxi Province. N, northern Shaanxi (the Loess Plateau in the northern part of Shaanxi Province); G, Guanzhong (Guanzhong Plain in the middle of Shaanxi Province); S, southern Shaanxi (the Qinba Mountainous region in the southern part of Shaanxi Province). The two blue lines are the northern and southern boundaries of Guanzhong.

were extracted from ITPCAS. This dataset was merged with meteorological data from the following sources: China Meteorological Administration data, reanalysis dataset of Princeton, Global Land Data Assimilation System (GLDAS) data, and Global Energy and Water Exchanges-Surface Radiation Budget (GEWEX-SRB) radiation data.

The Chinese Meteorological Disaster Canon-Shaanxi briefly summarizes the start-end months or seasons, duration, severity, areas and financial loss of drought events. However, drought areas were recorded vaguely. For example, the spatial extent was recorded as parts of the APC, or even parts of northern Shaanxi, Guanzhong and southern Shaanxi. Furthermore, the severity of drought is hard to quantify from these descriptions. Drought events extracted from records of the Chinese Meteorological Disaster Canon-Shaanxi (Zhai, 2005) during the period of 1979-2016 are shown in Table 1. It can be seen that Guanzhong and northern Shaanxi were more frequently affected by drought from 1979 to 2016.

In this study, metrological observations including precipitation and temperature during the period of 1979-2016 were downloaded from the China Meteorological Information Center (http://data.cma.cn/). Because these data were collected under rigorous quality control, no modifications were made for this study.

\subsection{Methods}

Drought characteristics of Shaanxi Province were analyzed by the following steps in this study. Firstly, SPEI was calculated with OMS at each standard meteorological station of Shaanxi Province and then interpolated into $10 \mathrm{~km} \times 10 \mathrm{~km}$ grids by OKI (termed as SPEI-OMS). Then, SPEI was calculated by temperature and precipitation data extracted from ITPCAS at $10 \mathrm{~km} \times 10 \mathrm{~km}$ grids of Shaanxi Province (termed as SPEI-ITPCAS). Both SPEI-OMS and SPEI-ITPCAS were calculated on seasonal and annual scales, and reclassified into drought and non-drought areas. The drought areas and period of drought occurrence were identified and then validated by comparison with historical records of drought events listed in Table 1. Secondly, spatial distributions of drought 
intensity, trend and temporal ranges for mutations of SPEI-ITPCAS in Shaanxi Province during the period of 1979-2016 were analyzed on seasonal (SPEI 3) and annual (SPEI 12) scales using the CDI index and the MK test.

Table 1 Historical records of typical drought events occurred in Shaanxi Province from the Chinese Meteorological Disaster Canon-Shaanxi

\begin{tabular}{ccc}
\hline Year & Season & Drought areas \\
\hline 1991 & Summer & South of northern Shaanxi, Guanzhong and southern Shaanxi (especially in Shangluo) \\
1994 & Winter & North of northern Shaanxi and Shangluo \\
1995 & Summer & South of northern Shaanxi and Guanzhong \\
1995 & Autumn & All regions ${ }^{*}$ \\
1997 & Spring & All regions \\
1997 & Summer & All regions \\
1998 & Autumn & All regions \\
1998 & Winter & All regions \\
1999 & Summer & All regions \\
2000 & Summer & All regions \\
2001 & Spring & Northern Shaanxi, northern Guanzhong and east of southern Shaanxi \\
2001 & Summer & Northern Shaanxi, Guanzhong and east of southern Shaanxi \\
2002 & Summer & All regions of Shaanxi Province except for Tongchuan and south of Yan'an \\
2008 & Winter & All regions
\end{tabular}

Note: ${ }^{*}$ means the drought events occurred in all ten prefecture-level cities. Northern Shaanxi refers to the Loess Plateau in the northern part of Shaanxi Province; Guanzhong refers to Guanzhong Plain in the middle of Shaanxi Province; southern Shaanxi refers to the Qinba Mountainous region in the southern part of Shaanxi Province.

\subsubsection{SPEI model}

SPEI (Vicente-Serrano et al., 2010a) reflects the characteristics of drought or waterlogging by calculating the difference between precipitation and potential evapotranspiration (PET). Currently, PET is generally calculated by Penman-Monteith (PM) equation (Allen et al., 1994) or Th (Thornthwaite, 1937) parameterization schemes. The PM scheme needs unavailable parameters such as reflectivity of ground objects in each grid of Shaanxi Province, whereas the Th scheme needs only latitude and monthly temperature data (Tsakiris et al., 2007) which are available for this study. Thus, the Th scheme was selected in this study. The calculation of SPEI was described as follows:

Firstly, monthly potential evapotranspiration $\left(\mathrm{PET}_{i}\right)$ was estimated by the $\mathrm{Th}$ scheme using Equation 1:

$$
\mathrm{PET}_{i}=16 \mathrm{~K}\left(\frac{10 T_{i}}{I}\right)^{m},
$$

where $\operatorname{PET}_{i}(\mathrm{~mm})$ is the potential evapotranspiration of month $i$; $\mathrm{K}$ is a correction coefficient computed as a function of the latitude and month; $T_{i}\left({ }^{\circ} \mathrm{C}\right)$ is the mean temperature of month $i$; $I$ is an annual heat index; and $m$ is a polynomial with parameter $I$.

Secondly, monthly water deficit or surplus $D_{i}$ was calculated by monthly precipitation $P_{i}$ and $\mathrm{PET}_{i}$ :

$$
D_{i}=P_{i}-\mathrm{PET}_{i} \text {. }
$$

The calculated $D_{i}$ values can be aggregated at different time scales. The water deficit or surplus $D_{i, j}^{k}$ in a given month $i$ and year $j$ at the time scale of $k(k \leq 12)$ months was defined as Equations 3 and 4: 


$$
\begin{gathered}
D_{i, j}^{k}=\sum_{l=13-k+i}^{12} D_{l, j-1}+\sum_{l=1}^{i} D_{l, j}(i<k), \\
D_{i, j}^{k}=\sum_{l=j-k+1}^{i} D_{i, j}(i \geq k),
\end{gathered}
$$

where $D_{l, j}(\mathrm{~mm})$ is the water deficit or surplus in the month $l$ of year $j$; and $D_{l, j-1}(\mathrm{~mm})$ is the water deficit or surplus in the month $l$ of year $j-1$.

According to the Kolmogorov-Smirnov test, the log-logistic distribution was the best to fit SPEI at time scales from 1 to 24 months compared with Pearson III and Gamma distribution (VicenteSerrano et al., 2010a; Yu et al., 2014). Thus, the log-logistic distribution was used to calculate SPEI after $D_{i, j}^{k}$ series were normally standardized. The probability distribution function $f(x)$ and cumulative distribution function $F(x)$ of the log-logistic distribution for $D_{i, j}^{k}$ series were defined in Equations 5 and 6, respectively:

$$
\begin{gathered}
f(x)=\frac{\beta}{\alpha}\left(\frac{x-\gamma}{\alpha}\right)^{\beta-1}\left[1+\left(\frac{x-\gamma}{\alpha}\right)^{\beta}\right]^{-2}, \\
F(x)=\left[1+\left(\frac{\alpha}{x-\gamma}\right)\right]^{-1},
\end{gathered}
$$

where $\alpha, \beta$ and $\gamma$ are the scale, shape and origin $\left(\gamma<D_{i}<\infty\right)$ parameters, respectively.

Finally, SPEI can be calculated by Equations 7 and 8 :

$$
\begin{gathered}
\mathrm{SPEI}=W-\frac{\mathrm{C}_{0}+\mathrm{C}_{1} W+\mathrm{C}_{2} W^{2}}{1+\mathrm{d}_{1}+\mathrm{d}_{2} W^{2}+\mathrm{d}_{3} W^{3}}, \\
W=\sqrt{-2 \ln (P)} .
\end{gathered}
$$

$W$ used in Equations 7 and 8 is the standardized value of $F(x)$. Constants used in Equation 7 are listed as follows: $\mathrm{C}_{0}=2.515517, \mathrm{C}_{1}=0.802853, \mathrm{C}_{2}=0.010328, \mathrm{~d}_{1}=1.432788, \mathrm{~d}_{2}=0.189269$ and $\mathrm{d}_{3}=0.001308$. In Equation 8 , if $P \leq 0.5$, then $P$ can be calculated as $P=1-F(x)$, where $P$ is the probability of exceeding the determination of $D_{i}$; whereas if $P>0.5$, thus $P$ can be calculated as

\begin{tabular}{|c|c|c|c|c|c|c|c|}
\hline & \multicolumn{3}{|c|}{ Drought } & \multirow{2}{*}{$\begin{array}{l}\text { Normal } \\
\text { Normal }\end{array}$} & \multicolumn{3}{|c|}{ Waterlogging } \\
\hline & Exceptional & Severe & Moderate & & Moderate & Severe & Exceptional \\
\hline SPEI & $\leq-2.0$ & $-2.0--1.0$ & $-1.0--0.5$ & $-0.5-0.5$ & $0.5-1.0$ & $1.0-2.0$ & $\geq 0.0$ \\
\hline
\end{tabular}
$P=F(x)$.

In this study, SPEI was calculated on seasonal (SPEI 3) and annual (SPEI 12) scales. Categories of drought and waterlogging classified by SPEI are shown in Table 2.

Table 2 Categories of drought and waterlogging classified by SPEI (Standard Precipitation Evapotranspiration Index)

2.3.2 Ordinary Kriging interpolation (OKI)

OKI makes an unbiased estimation of variables at target locations by a weighted linear combination of neighboring observations. It has been widely used as a popular Kriging technique to interpolate meteorological factors. Previous studies showed that OKI outperformed in precipitation interpolation compared with methods including Inverse Distance Weighted, Thiessen Polygons and Simple Kriging (Zhang and Srinivasan, 2009; Szcześniak and Piniewski, 2015). Details of using OKI for precipitation interpolation can be found in the original study of Goovaerts (2000).

2.3.3 Cumulative drought intensity (CDI)

CDI on seasonal and annual scales can integrate the drought severity and frequency of various forms of drought, providing the ways to evaluate drought over the long-term period (Kim et al., 2002; Loukas et al., 2008). It can well indicate the cumulative impact of drought on human society in a specific region. 
We calculated CDI according to the following steps: firstly, we calculated the SPEI-ITPCAS of each grid on seasonal and annual scales; secondly, we accumulated the drought (SPEI-ITPCAS lower than -0.5) according to the temporal range (Kim et al., 2002; Loukas et al., 2008). The larger the absolute cumulative SPEI-ITPCAS is, the greater the CDI is. Drought areas with cumulative SPEI-ITPCAS less than -14.0 were calculated by summing the areas of the grids with high CDI values.

\subsubsection{Mann-Kendall (MK) test}

MK test (Mann, 1945; Kendall, 1975) was used in this study for trend and trend mutation tests. MK test is widely applied in trend analysis of meteorological and environmental factors, such as precipitation, temperature and runoff (Ahmad et al., 2015). The principle of MK trend test was described below.

MK trend test assumed that the original time series $x_{t}=\left(x_{1}, x_{2}, \ldots, x_{n}\right)$ was random and independent with no significant trend. The statistical variable $S$ was defined in Equation 9:

$$
S=\sum_{i=1}^{n-1} \sum_{j=i+1}^{n} \operatorname{sgn}\left(x_{j}-x_{i}\right)
$$

where sgn is a symbolic function; and $x_{j}$ and $x_{i}$ are the values of variables of the time series. If $n \geq 10$, $S$ can be approximately normally distributed. In addition, variable $Z$ was used to show the results of significance test, which was defined as Equation 10:

$$
Z=\left\{\begin{array}{cc}
(S-1) / \sqrt{\operatorname{var}(S)} & (S>0) \\
0 & (S=0) . \\
(S+1) / \sqrt{\operatorname{var}(S)} & (S<0)
\end{array}\right.
$$

In a two-sided hypothesis test, positive and negative values of $Z$ corresponded to the upward and downward trends, respectively. If $|Z| \leq Z_{1-\alpha / 2}(\alpha$ is the significance level), the original hypothesis was accepted, namely, the time series data had no significant trend; otherwise, the hypothesis was rejected, and the time series data had a significant trend. Moreover, If $|Z| \geq 1.28,1.64$ and 2.32, the significance test was accepted at significance levels of $90 \%, 95 \%$ and $99 \%$, respectively.

In this study, we conducted the mutation test of MK according to the following descriptions.

The MK trend variation test assumed that the original time series $x_{t}=\left(x_{1}, x_{2}, \ldots, x_{n}\right)$ was random and independent with no significant trend. The statistical variable $U F_{k}$ was the forward sequence and was defined as Equation 11:

$$
\begin{gathered}
U F_{k}=\frac{S_{k}-E\left(S_{k}\right)}{\sqrt{\operatorname{var}\left(S_{k}\right)}}, k=1,2, \ldots, n, \\
S_{k}=\sum_{i=1}^{k} r_{i}, k=2,3, \ldots, n, \\
r_{i}=\left\{\begin{array}{l}
+1\left(x_{i}>x_{j}\right) \\
0\left(x_{i} \leq x_{j}\right)
\end{array}\right) \\
E\left(S_{k}\right)=\frac{k(k-1)}{4}, k=2,3, \ldots, n, \\
\operatorname{var}\left(S_{k}\right)=\frac{k(k-1)(2 k+5)}{72}, k=2,3, \ldots, n,
\end{gathered}
$$

where $S_{k}$ represents the total numbers of $x_{j}$ preceding all $x_{i}$ and is defined in Equations 12 and 13; $E\left(S_{k}\right)$ represents the expectation of $S_{k}$; $\operatorname{var}\left(S_{k}\right)$ represents the variance of $S_{k}$; and $k$ represents the sequence number. For each $x_{i}, r_{i}$ represents the total numbers of $x_{j}$ which is smaller than $x_{i}(j<i)$. Statistical parameter $U F_{k}$ obeys the normal distribution. If $\left|U F_{k}\right|>U_{\alpha / 2}$, the time series data had a significant decreasing or increasing trend. $U F^{\prime}{ }_{k}$ was calculated by the same Equations $11-14$ with 
the reversed times series of $x_{t}$. When the two curves $U F_{k}$ and $U F^{\prime}{ }_{k}$ intersected between the critical boundary $\left(y= \pm U_{\alpha}\right)$, the moment of intersection was the trend variation begins.

\section{Results}

\subsection{Validation of SPEI-ITPCAS and SPEI-OMS}

Figures 2 and 3 show the drought areas of Shaanxi Province detected from SPEI-ITPCAS and SPEI-OMS, respectively, for years and seasons corresponding to typical drought events. It can be seen that the distribution of drought areas detected from SPEI-ITPCAS and SPEI-OMS were similar in summer of 1991, spring of 1997, autumn of 1998, winter of 1998 and spring of 2001 (Figs. 2 and 3), which accounted for $31.3 \%$ of the total seasons. In contrast, there were significant discrepancies of drought areas between the remaining seasons, indicating that meteorological data extracted from OMS and ITPCAS were not spatially consistent with drought monitoring for most of the seasons. As shown in Table 1, drought occurred in all 10 APCs of Shaanxi Province in nine seasons: springs of 1997 and 2001; summers of 1997 and 1999; autumns of 1995, 1998 and 2010; and winters of 1998 and 2008. In the above nine seasons, the distribution of drought areas identified from SPEI-ITPCAS (Fig. 2) was consistent with the historical records from the Chinese Meteorological Disaster Canon-Shaanxi (Table 1). In contrast, in summer of 1999 and winter of 2008, drought areas identified from SPEI-OMS (Fig. 3) were different with the historical drought records from the Chinese Meteorological Disaster Canon-Shaanxi (Table 1), with the absence of north of Guanzhong.

Table 3 lists the discrepancies of drought areas detected from different sources, i.e., historical drought records (Table 1) and SPEI-ITPCAS (Fig. 2), while Table 4 shows the discrepancies of drought areas between historical drought records (Table 1) and SPEI-OMS (Fig. 3). Compared with the seasons and regions in which drought events occurred, the discrepancies of drought areas between the two SPEI results and historical records happened in summer and in north of Guanzhong and northern Shaanxi frequently. Discrepancies of drought areas listed in Table 3 were similar to those in the same season listed in Table 4 . However, Table 4 presents more discrepancies than Table 3. Discrepancies of drought areas shown in Table 4 were more likely to occur in Yulin, Tongchuan and Weinan, which were frequently affected by drought. In conclusion, the detection of drought areas from SPEI-ITPCAS presented a higher accuracy than that from SPEI-OMS. Therefore, SPEI-ITPCAS was adopted to analyze the spatial-temporal characteristics of drought in Shaanxi Province.

\subsection{Distribution of CDI}

Figure 4 shows that the cumulative SPEI-ITPCAS (SPEI-ITPCAS lower than -0.5) in Shaanxi Province from 1979 to 2016 was within -10.0 to -20.0 on seasonal and annual scales. On seasonal and annual scales, the cumulative SPEI-ITPCAS was within -10.0 to -14.0 in most regions of Shaanxi Province. When the cumulative SPEI-ITPCAS was less than-14.0, the region was defined as a typical area with high CDI values. On the winter scale, the cumulative SPEI-ITPCAS was within -16.0 to -20.0 in most regions of Shaanxi Province and the CDI values were higher than those on other seasonal and annual scales. Figure 4a indicates that areas with higher CDI values in spring were mainly distributed on the eastern and western boundaries of Guanzhong and in southern Shaanxi (A1 and A2), especially in southeast of Guanzhong and northwest of southern Shaanxi (A2) with an area of more than $2000 \mathrm{~km}^{2}$ and high CDI values on seasonal and annual scales. In summer, areas with high CDI values were mainly distributed in Yulin (B1) and Shangluo (B2; Fig. 4b). In autumn, areas with high CDI values were located in Yan'an (C1) and Hanzhong (C2; Fig. 4c). On an annual scale, the CDI values in western Yulin (E1) and eastern Shangluo and Weinan (E2; Fig. 4e) were high. However, Figure 4d indicates that the CDI values in winter in the whole region were abnormally high, which is not consistent with the historical drought records (Zhai, 2005). Thus, the CDI in winter was not analyzed in this section. 

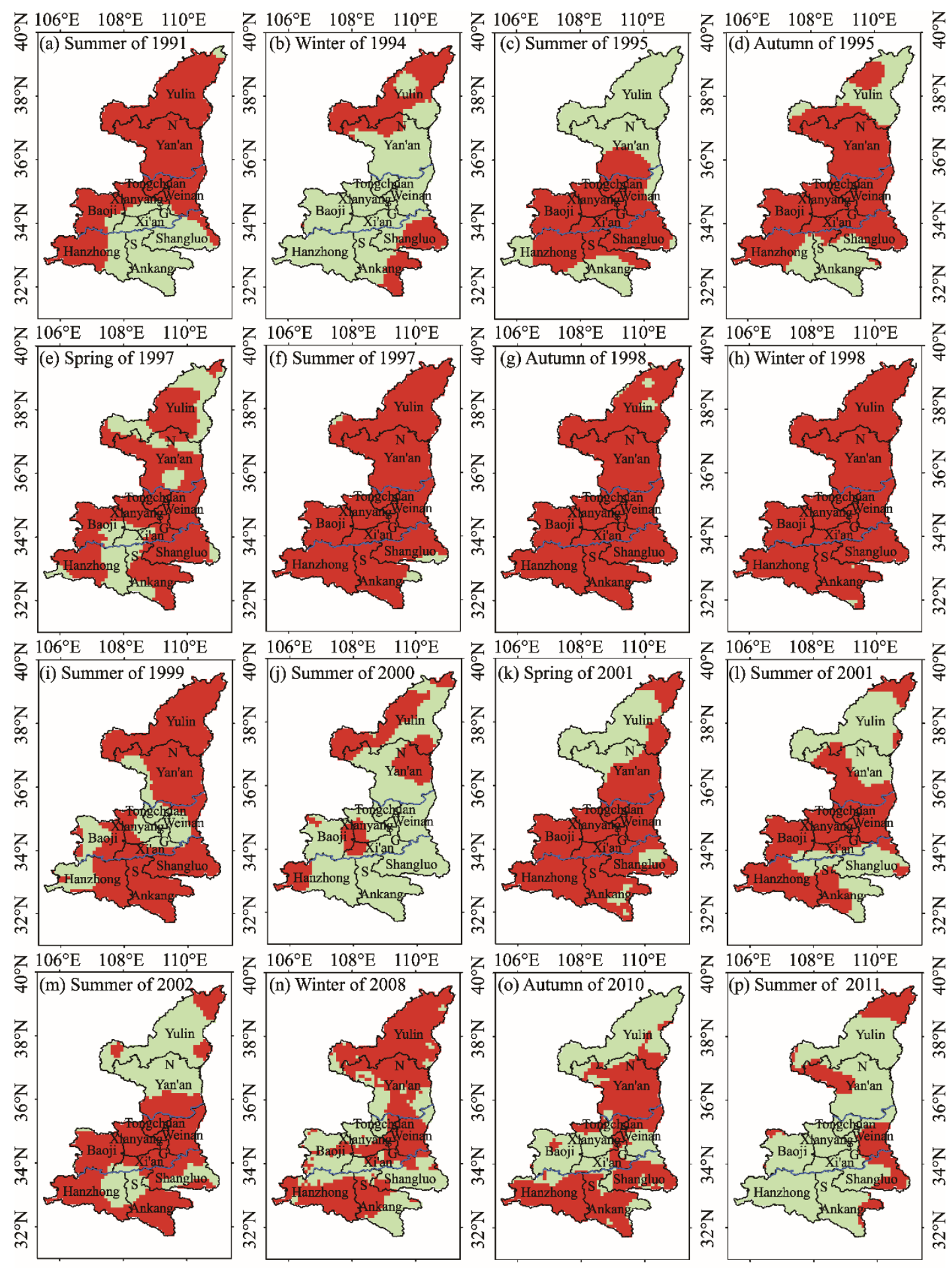

乙 $106^{\circ} \mathrm{E} \quad 108^{\circ} \mathrm{E} \quad 110^{\circ} \mathrm{E}$
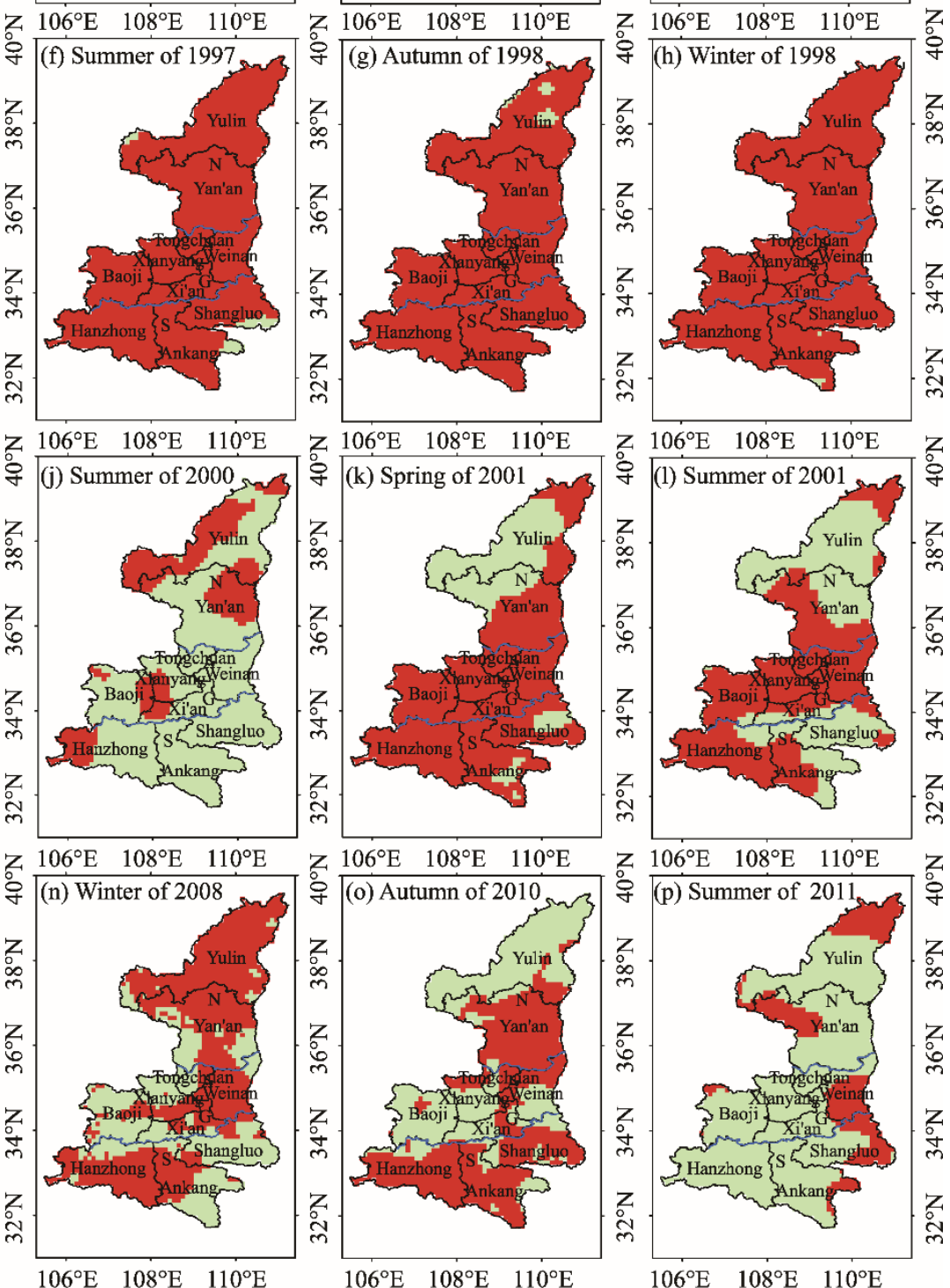

Legend

Legend

Non-drought area

$\stackrel{0}{0} \quad 200 \quad 400 \mathrm{~km}$

Approved No. 陕S (2020) 018

Fig. 2 Spatial distributions of drought and non-drought areas in Shaanxi Province detected from SPEI-ITPCAS (Standard Precipitation Evapotranspiration Index calculated with data from China Meteorological Forcing Dataset produced by the Institute of Tibetan Plateau Research, Chinese Academy of Sciences). Drought areas were detected as SPEI-ITPCAS lower than -0.5 (Table 2). The two blue lines are the northern and southern boundaries of Guanzhong. 

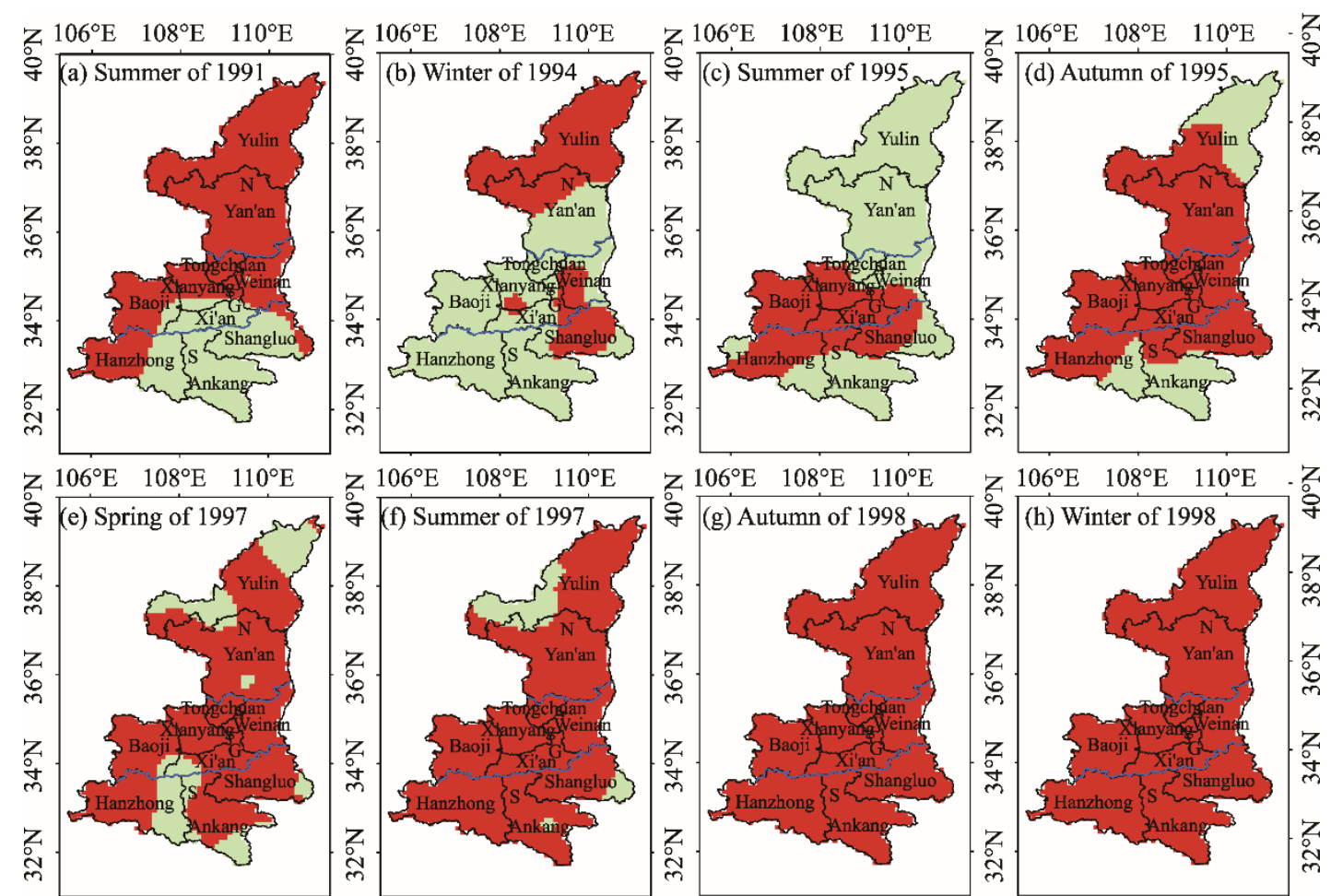

乙 $106^{\circ} \mathrm{E} \quad 108^{\circ} \mathrm{E} \quad 110^{\circ} \mathrm{E}$
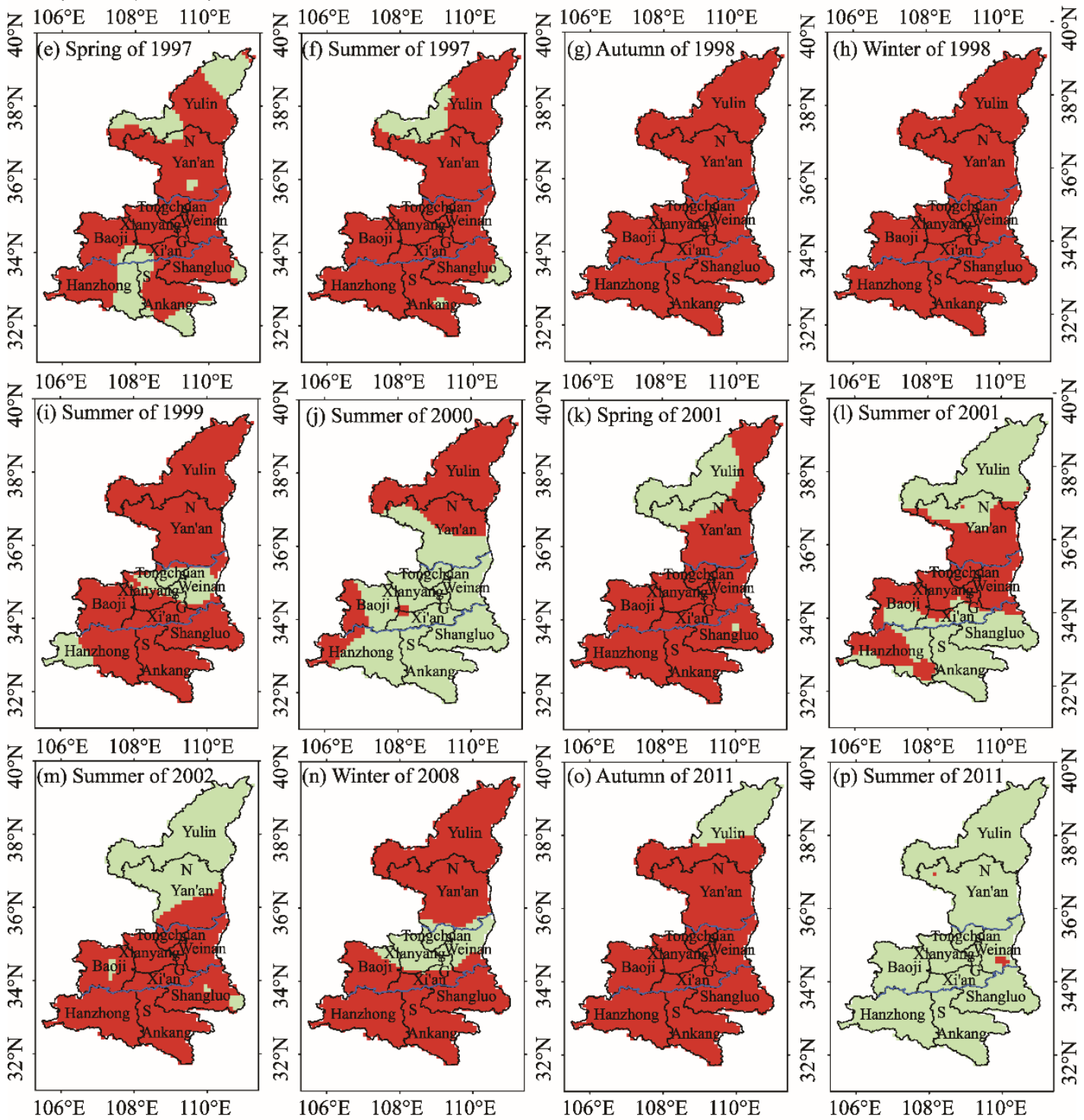

$106^{\circ} \mathrm{E} \quad 108^{\circ} \mathrm{E} \quad 110^{\circ} \mathrm{E}$ Legend

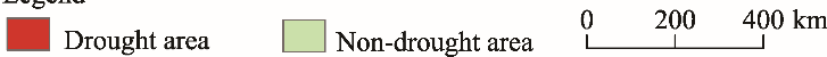

Approved No. 陕S (2020) 018

Fig. 3 Spatial distributions of drought and non-drought areas in Shaanxi Province detected from SPEI-OMS (Standard Precipitation Evapotranspiration Index calculated with data from observations of meteorological stations). Drought areas were detected as SPEI-OMS lower than -0.5 (Table 2). The two blue lines are the northern and southern boundaries of Guanzhong. 
Table 3 Discrepancies of drought areas detected from historical drought records of Chinese Meteorological Disaster Canon-Shaanxi and SPEI-ITPCAS

\begin{tabular}{ccc}
\hline Year & Season & Discrepancy of drought areas \\
\hline 1991 & Summer & North of northern Shaanxi \\
1994 & Winter & East of Ankang \\
2000 & Summer & North of Guanzhong \\
2002 & Summer & Tongchuan and south of Yan'an \\
\hline
\end{tabular}

Note: SPEI-ITPCAS, Standard Precipitation Evapotranspiration Index calculated with data from China Meteorological Forcing Dataset produced by the Institute of Tibetan Plateau Research, Chinese Academy of Sciences.

Table 4 Discrepancies of drought areas detected from historical drought records of Chinese Meteorological Disaster Canon-Shaanxi and SPEI-OMS

\begin{tabular}{ccc}
\hline Year & Season & Discrepancy of drought areas \\
\hline 1991 & Summer & North of northern Shaanxi \\
1994 & Winter & Part of Weinan \\
1995 & Summer & South of northern Shaanxi and north of Guanzhong \\
1999 & Summer & North of Guanzhong \\
2000 & Summer & North of Guanzhong \\
2001 & Summer & Yulin \\
2002 & Summer & Tongchuan, south of Yan'an and Yulin \\
2008 & Winter & Tongchuan, Xianyang and Weinan \\
2011 & Summer & Guanzhong and parts of northern Shaanxi \\
\hline
\end{tabular}

Note: SPEI-OMS, Standard Precipitation Evapotranspiration Index calculated with data from observations of meteorological stations.

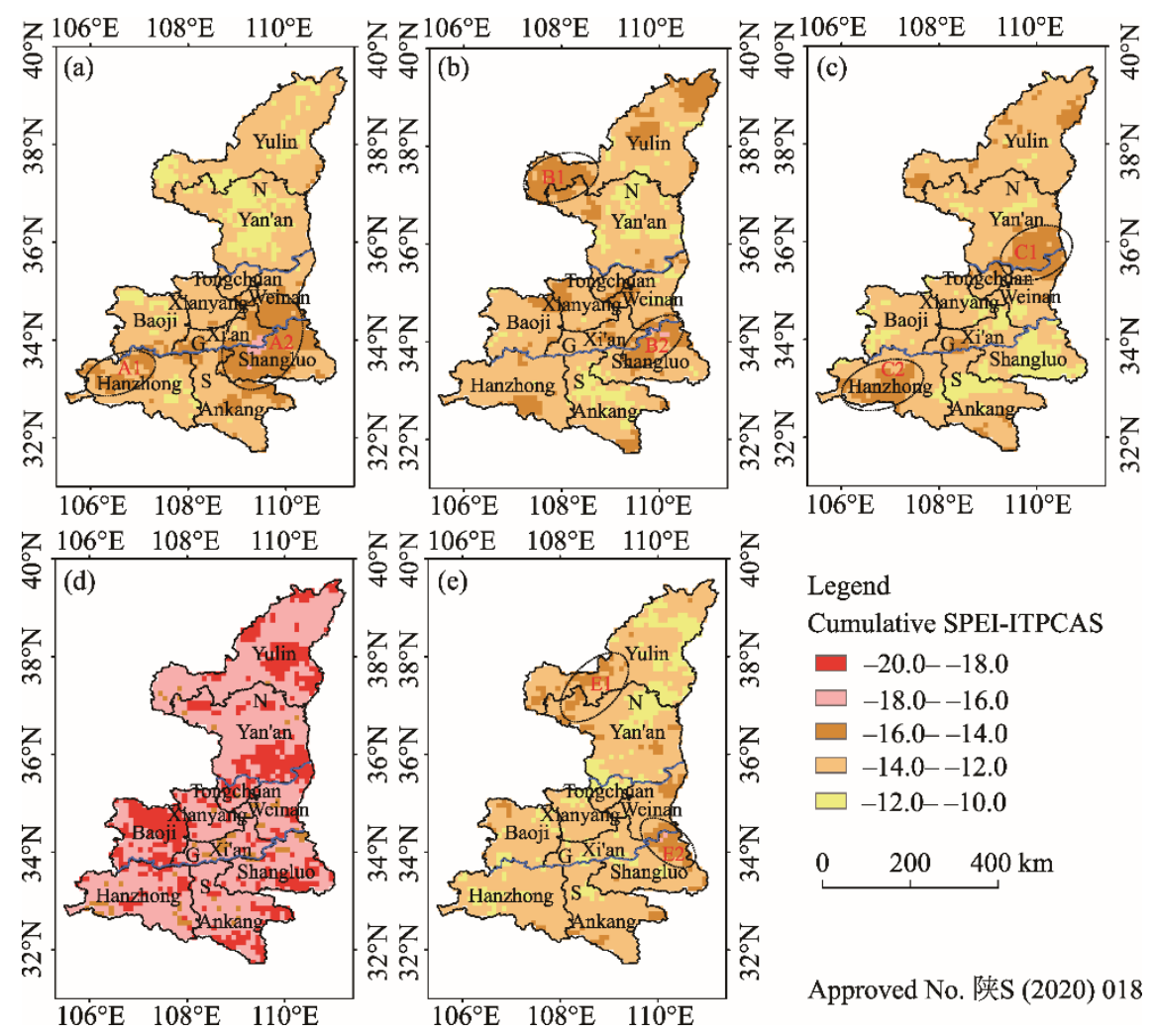

Fig. 4 Spatial distributions of cumulative drought intensity (CDI) in spring (a), summer (b), autumn (c) and winter (d), and on an annual scale (e) in Shaanxi Province from 1979 to 2016. A1 and A2 represent regions with high CDI values in spring; $\mathrm{B} 1$ and $\mathrm{B} 2$ represent regions with high $\mathrm{CDI}$ values in summer; $\mathrm{C} 1$ and $\mathrm{C} 2$ represent regions with high CDI values in autumn; E1 and E2 represent regions with high CDI values on an annual scale. The two blue lines are the northern and southern boundaries of Guanzhong. 
Frequencies of severe and exceptional drought in Shaanxi Province from 1979 to 2016 are shown in Table 5. The rank of drought frequency on different scales was as follows: summer $>$ spring $>$ annual $>$ autumn; however, the discrepancies between different scales were not significant. From Figure 4 and Table 5 we can conclude that, drought occurred most frequently and seriously in summer, followed by spring. Southeast of Guanzhong and northwest of southern Shaanxi were the most sensitive areas to the impact of drought with the highest CDI value and the largest drought area in spring and summer and on an annual scale. In addition, eastern Yulin, southern Yan'an and Hanzhong were also likely to be affected in summer and autumn.

Table 5 Frequencies of severe and exceptional drought (SPEI-ITPCAS lower than -1.0) and regions with high cumulative drought intensity (CDI) values on seasonal and annual scales in Shaanxi Province

\begin{tabular}{|c|c|c|}
\hline $\begin{array}{l}\text { Season/annual } \\
\text { scale }\end{array}$ & $\begin{array}{l}\text { Severe and exceptional } \\
\text { drought (times) }\end{array}$ & Regions with high CDI values \\
\hline Spring & 12,331 & $\begin{array}{l}\text { Part of Hanzhong (A1), with an area of about } 500 \mathrm{~km}^{2} \text {; part of Shangluo, } \\
\text { Weinan, Ankang and Xi'an (A2), with an area of about } 2000 \mathrm{~km}^{2}\end{array}$ \\
\hline Summer & 12,937 & $\begin{array}{l}\text { Part of Yulin (B1), with an area of about } 820 \mathrm{~km}^{2} \text {; part of Shangluo, } \\
\text { Weinan and Xi'an (B2), with an area of about } 780 \mathrm{~km}^{2}\end{array}$ \\
\hline Autumn & 11,860 & $\begin{array}{l}\text { Part of Yan'an (C1), with an area of about } 1000 \mathrm{~km}^{2} ; \text { part of Hanzhong } \\
\text { (C2), with an area of about } 700 \mathrm{~km}^{2}\end{array}$ \\
\hline Annual & 12,250 & $\begin{array}{l}\text { Part of Yulin (E1), with an area of about } 440 \mathrm{~km}^{2} \text {; part of Shangluo (E2), } \\
\text { with an area of about } 490 \mathrm{~km}^{2}\end{array}$ \\
\hline
\end{tabular}

Note: A1, A2, B1, B2, C1, C2, E1 and E2 are depicted in Figure 4.

\subsection{MK test of precipitation, temperature and SPEI-ITPCAS}

As shown in Figures 5 and 6, temperature presented a significant increasing trend $(Z \geq 1.28)$ in most regions of Shaanxi Province on seasonal and annual scales. Only part of Ankang showed an insignificant decreasing trend $(-1.28 \leq Z \leq 0.00)$ in summer, autumn and winter. However, the significance and variation trend of precipitation and SPEI-ITPCAS in MK test varied in most regions of Shaanxi Province on the seasonal scale. Tables 6 and 7 showed the significance and variation trends of precipitation and SPEI-ITPCAS on seasonal and annual scales in Shaanxi Province, respectively. In spring, the upward trend of precipitation occurred in most regions of Shaanxi Province, except for parts of Guanzhong. Moreover, the temperature showed a significant upward trend at $99 \%$ confidence level. The SPEI-ITPCAS showed a drying trend in most regions of Shaanxi Province, except for part of southern Shaanxi. The variation trends of SPEI-ITPCAS and precipitation were opposite in most regions, which indicated that the abnormal increase of temperature dominated meteorological processes, leading to a drying trend in most regions.

In summer, the downward trend of precipitation together with the significant upward trend of temperature led to a general drying trend in most regions of Shaanxi Province. This drying trend was especially significant in parts of Yan'an and Guanzhong, and west of southern Shaanxi. Almost all of the five APCs in Guanzhong showed a significant drying trend. The situation was consistent with historical drought records, which indicated that drought in spring and summer was quite serious in Guanzhong and northern Shaanxi (Zhai, 2005).

In autumn and winter, the significant upward trend of precipitation mainly occurred in northern Shaanxi, while the downward trend mainly occurred in Guanzhong and southern Shaanxi. The temperature showed a significant upward trend in all regions. The variation trends of SPEI-ITPCAS reflected a composite interaction of precipitation and temperature with remarkable spatial heterogeneity in Shaanxi Province. In conclusion, we found a significant wetting trend in northern Shaanxi and a significant drying trend in parts of Xi'an, Weinan, Hanzhong and Ankang.

The variation trends of precipitation and temperature in northern Shaanxi, Guanzhong and southern Shaanxi on an annual scale were similar with those on autumn and winter scales. The wetting trend in northern Shaanxi was less significant than the upward trend of precipitation, and the drying trends in Guanzhong and southern Shaanxi were more significant than the downward trend of precipitation on an annual scale. The phenomena showed that the significant upward trend of temperature in Shaanxi Province counteracted the upward trend of precipitation (leading to a less significant wetting trend in northern Shaanxi) and interacted with the downward trend of precipitation (leading to a more significant drying trend in Guanzhong and southern Shaanxi). 
Precipitation
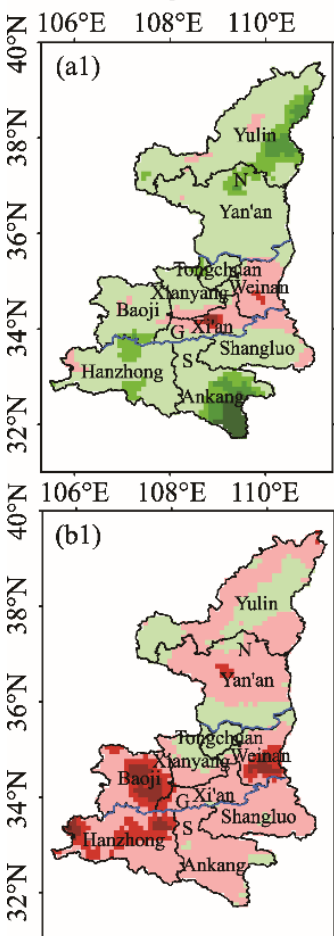

乙 $106^{\circ} \mathrm{E} \quad 108^{\circ} \mathrm{E} \quad 110^{\circ} \mathrm{E}$

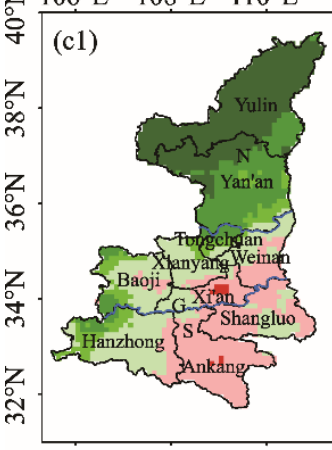

号

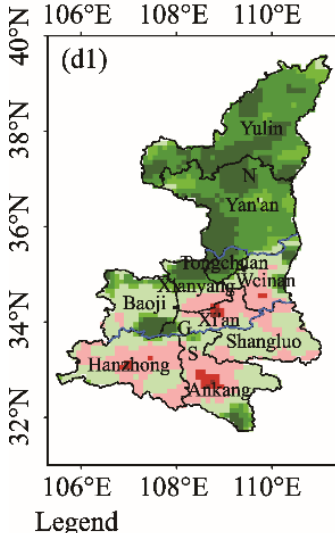

Temperature

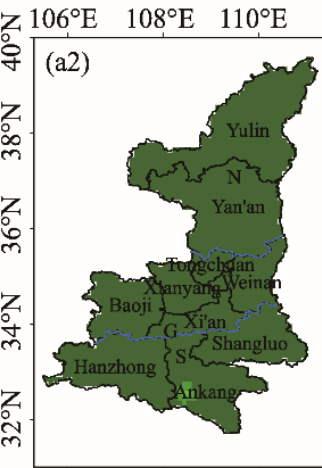

乙 $106^{\circ} \mathrm{E} \quad 108^{\circ} \mathrm{E} \quad 110^{\circ} \mathrm{E}$

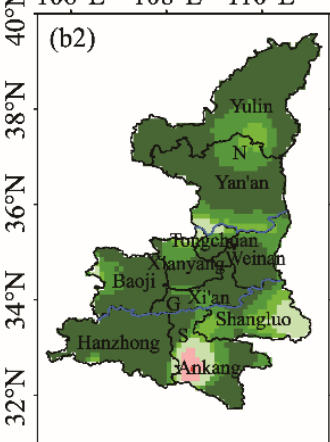

乙 $106^{\circ} \mathrm{E} \quad 108^{\circ} \mathrm{E} \quad 110^{\circ} \mathrm{E}$

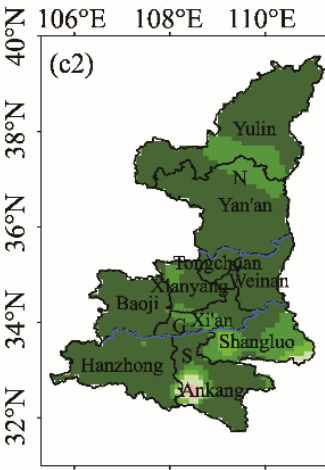

$106^{\circ} \mathrm{E} \quad 108^{\circ} \mathrm{E} \quad 110^{\circ} \mathrm{E}$

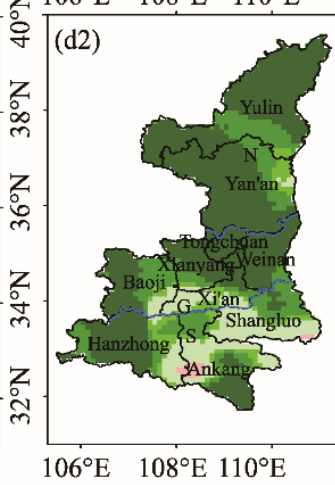

SPEI-ITPCAS

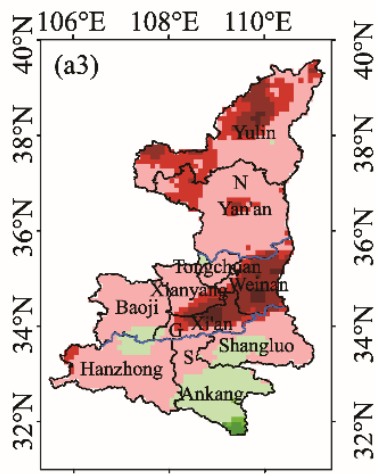

Z $106^{\circ} \mathrm{E} \quad 108^{\circ} \mathrm{E} \quad 110^{\circ} \mathrm{E}$

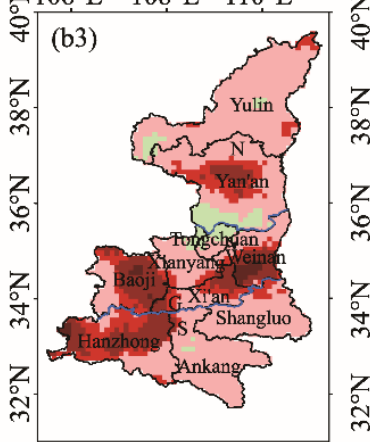

乙 $106^{\circ} \mathrm{E} \quad 108^{\circ} \mathrm{E} \quad 110^{\circ} \mathrm{E}$ 乙

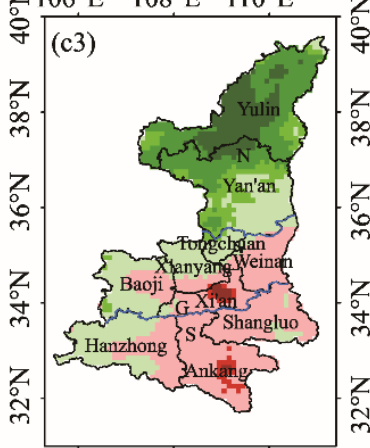

$\mathrm{Z} 106^{\circ} \mathrm{E} \quad 108^{\circ} \mathrm{E} \quad 110^{\circ} \mathrm{E}$

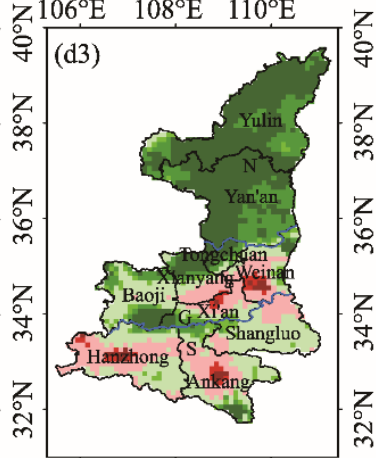

$106^{\circ} \mathrm{E} \quad 108^{\circ} \mathrm{E} \quad 110^{\circ} \mathrm{E}$
$Z$ value of MK test
$<-2.32$
$-2.32--1.64$
$-1.64--1.28$
$0 \quad 200 \quad 400 \mathrm{~km}$
$\square 0.00-1.28 \square 1.28-1.64$
$1.64-2.32$
$-1.28-0.00$
$>2.32$ Approved No. 陕S (2020) 018

Fig. 5 Spatial distributions of variable $Z$ of Mann-Kendall (MK) test for precipitation, temperature and SPEIITPCAS in spring (a1-a3), summer (b1-b3), autumn (c1-c3) and winter (d1-d3) in Shaanxi Province. The two blue lines are the northern and southern boundaries of Guanzhong. 


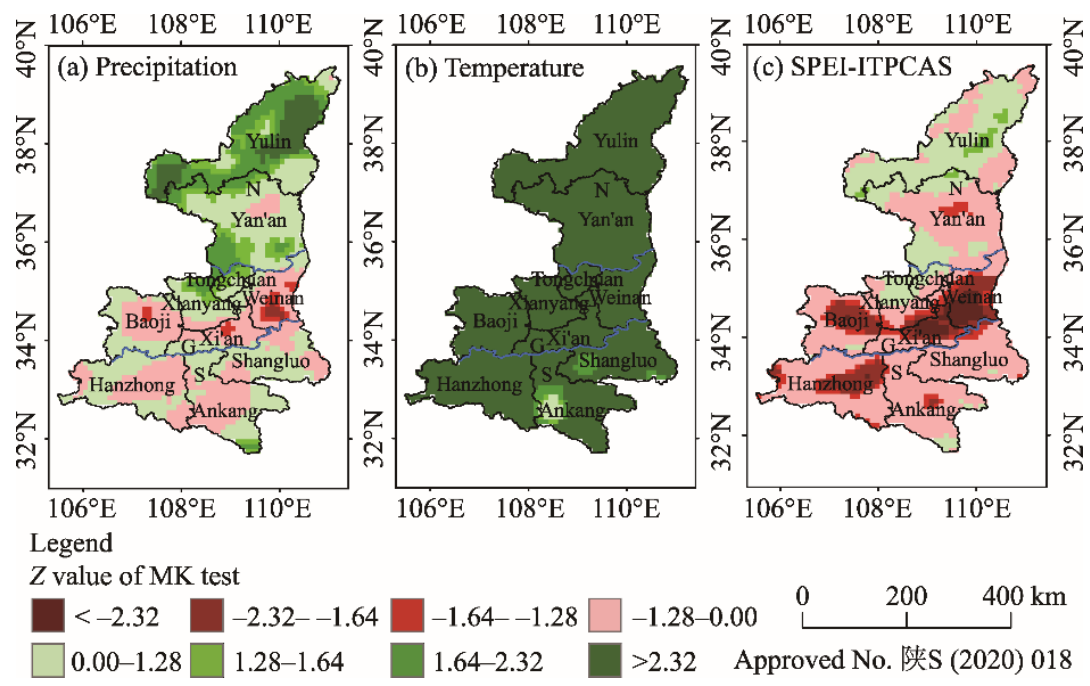

Fig. 6 Spatial distributions of variable $Z$ of MK test for precipitation (a), temperature (b) and SPEI-ITPCAS (c) on an annual scale in Shaanxi Province. The two blue lines are the northern and southern boundaries of Guanzhong.

Table 6 Significance and trend of precipitation in Mann-Kendall (MK) test on seasonal and annual scales in Shaanxi Province

\begin{tabular}{|c|c|c|c|}
\hline Season/annual scale & $Z$ value & Trend & Regions \\
\hline \multirow[t]{4}{*}{ Spring } & $Z \geq 0.00$ & Upward & All of Shaanxi Province except for Xi'an and Weinan \\
\hline & $Z \geq 1.28$ & Upward $^{*}$ & Parts of Yulin and Ankang \\
\hline & $Z \leq 0.00$ & Downward & Xi'an and Weinan \\
\hline & $Z \leq-1.28$ & Downward ${ }^{*}$ & Parts of Xi'an and Weinan \\
\hline \multirow[t]{4}{*}{ Summer } & $Z \geq 0.00$ & Upward & Tongchuan and parts of Yulin and Yan'an \\
\hline & $Z \geq 1.28$ & Upward $^{*}$ & \\
\hline & $Z \leq 0.00$ & Downward & $\begin{array}{l}\text { Parts of northern Shaanxi, Guanzhong (except for Tongchuan) and } \\
\text { southern Shaanxi }\end{array}$ \\
\hline & $Z \leq-1.28$ & Downward* & Parts of Baoji, Hanzhong and Weinan \\
\hline \multirow[t]{4}{*}{ Autumn } & $Z \geq 0.00$ & Upward & $\begin{array}{c}\text { All of Shaanxi Province except for parts of Weinan, Xi'an, } \\
\text { Shangluo and Ankang }\end{array}$ \\
\hline & $Z \geq 1.28$ & Upward* & Yulin and Yan'an \\
\hline & $Z \leq 0.00$ & Downward & Parts of Weinan, Xi'an, Shangluo and Ankang \\
\hline & $Z \leq-1.28$ & Downward ${ }^{*}$ & Parts of Xi'an and Ankang \\
\hline \multirow[t]{4}{*}{ Winter } & $Z \geq 0.00$ & Upward & $\begin{array}{l}\text { All of Shaanxi Province except for parts of Weinan, Xi'an, Ankang } \\
\text { and Hanzhong }\end{array}$ \\
\hline & $Z \geq 1.28$ & Upward $^{*}$ & Yulin, Yan'an, and parts of Tongchuan, Xianyang and Baoji \\
\hline & $Z \leq 0.00$ & Downward & Parts of Weinan, Xi'an, Ankang and Hanzhong \\
\hline & $Z \leq-1.28$ & Downward ${ }^{*}$ & Parts of Xi'an and Ankang \\
\hline \multirow[t]{4}{*}{ Annual } & $Z \geq 0.00$ & Upward & Northern Shaanxi, parts of Guanzhong and southern Shaanxi \\
\hline & $Z \geq 1.28$ & Upward $^{*}$ & Parts of Yulin, Yan'an and Tongchuan \\
\hline & $Z \leq 0.00$ & Downward & Parts of Guanzhong and southern Shaanxi \\
\hline & $Z \leq-1.28$ & Downward* & Parts of Baoji, Xi'an and Weinan \\
\hline
\end{tabular}

Note: ${ }^{*}$ means that the confidence level of trend is above $90 \%$.

\subsection{Temporal ranges for mutations of SPEI-ITPCAS on seasonal and annual scales}

As shown in Figure 7, the temporal ranges for mutations of SPEI-ITPCAS can be notably discerned on seasonal and annual scales in Shaanxi Province. For example, mutations of SPEI-ITPCAS occurred during the period of 1990-2000 in west of Shaanxi Province and east of Guanzhong in spring (Fig. 7a). In summer, they occurred during the period of 1990-2000 in west and middle of Guanzhong (Fig. 7b). In autumn, they appeared after the year 2000 in north of northern Shaanxi 
Table 7 Significance and trend of SPEI-ITPCAS in MK test on seasonal and annual scales in Shaanxi Province

\begin{tabular}{|c|c|c|c|}
\hline $\begin{array}{l}\text { Season/annual } \\
\text { scale }\end{array}$ & $Z$ value & Trend & Regions \\
\hline \multirow[t]{4}{*}{ Spring } & $Z \geq 0.00$ & Wetting & Parts of southern Shaanxi and Baoji \\
\hline & $Z \geq 1.28$ & Wetting* & Parts of Ankang \\
\hline & $Z \leq 0.00$ & Drying & All of Shaanxi Province except for parts of southern Shaanxi and Baoji \\
\hline & $Z \leq-1.28$ & Drying ${ }^{*}$ & Part of Yulin, Yan'an, and middle and east of Guanzhong \\
\hline \multirow[t]{4}{*}{ Summer } & $Z \geq 0.00$ & Wetting & Parts of Tongchuan and south of Yan'an \\
\hline & $Z \geq 1.28$ & Wetting $^{*}$ & \\
\hline & $Z \leq 0.00$ & Drying & $\begin{array}{l}\text { All of Shaanxi Province except for parts of Tongchuan and south of } \\
\text { Yan'an }\end{array}$ \\
\hline & $Z \leq-1.28$ & Drying ${ }^{*}$ & West of southern Shaanxi, and parts of Yan'an and Guanzhong \\
\hline \multirow[t]{4}{*}{ Autumn } & $Z \geq 0.00$ & Wetting & Northern Shaanxi, west and north of Guanzhong, and east of Hanzhong \\
\hline & $Z \geq 1.28$ & Wetting $^{*}$ & Yulin and north of Yan'an \\
\hline & $Z \leq 0.00$ & Drying & Middle and eastern parts of Guanzhong and southern Shaanxi \\
\hline & $Z \leq-1.28$ & Drying ${ }^{*}$ & Parts of Xi'an and Ankang \\
\hline \multirow[t]{4}{*}{ Winter } & $Z \geq 0.00$ & Wetting & Northern Shaanxi, and parts of Gaunzhong and southern Shaanxi \\
\hline & $Z \geq 1.28$ & Wetting* & Northern Shaanxi, and parts of Gaunzhong and southern Shaanxi \\
\hline & $Z \leq 0.00$ & Drying & Parts of Xi'an, Weinan, Hanzhong and Ankang \\
\hline & $Z \leq-1.28$ & Drying ${ }^{*}$ & Parts of Xi'an, Weinan, Hanzhong and Ankang \\
\hline \multirow[t]{4}{*}{ Annual } & $Z \geq 0.00$ & Wetting & Yulin, and parts of Yan'an, Tongchuan and Xianyang \\
\hline & $Z \geq 1.28$ & Wetting $^{*}$ & \\
\hline & $Z \leq 0.00$ & Drying & $\begin{array}{c}\text { All of Shaanxi Province except for Yulin, and parts of Yan'an, } \\
\text { Tongchuan and Xianyang }\end{array}$ \\
\hline & $Z \leq-1.28$ & Drying ${ }^{*}$ & Parts of Guanzhong, Hanzhong and Ankang \\
\hline
\end{tabular}

Note: ${ }^{*}$ means that the confidence level of trend is above $90 \%$.
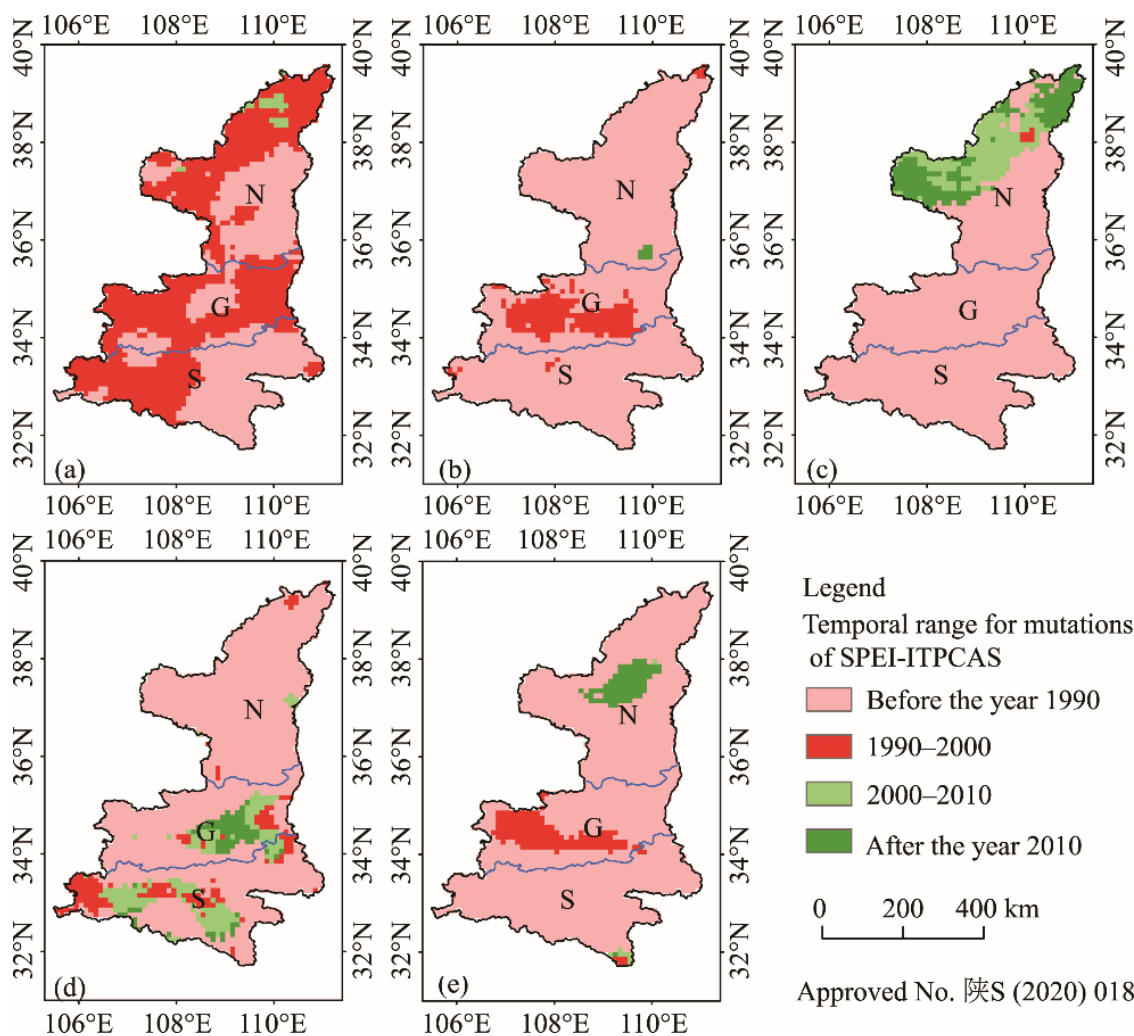

Legend

Temporal range for mutations of SPEI-ITPCAS

Before the year 1990

1990-2000

2000-2010

After the year 2010

$0 \quad 200 \quad 400 \mathrm{~km}$

Approved No. 陕S (2020) 018

Fig. 7 Temporal ranges for mutations of SPEI-ITPCAS in spring (a), summer (b), autumn (c) and winter (d), and on an annual scale (e) in Shaanxi Province. The two blue lines are the northern and southern boundaries of Guanzhong. 
(Fig. 6c). In winter, they occurred after the year 2000 in east and middle of Guanzhong and in parts of southern Shaanxi (Fig. 7d). On an annual scale, mutations of SPEI-ITPCAS occurred during the period of 1990-2000 in west and middle of Guanzhong, and after the year 2000 in parts of northern Shaanxi (Fig. 7e). In conclusion, the regional and temporal ranges for mutations of SPEI-ITPCAS differed on seasonal and annual scales, and most mutations happened before the year 1990. As Shaanxi Province has three types of terrain with comparably diverse climates (i.e., cold and arid plateau in the north, mild plain in the middle, and wet and warm mountainous regions in the south), the regional responses to climate change varied. The discrepancies of temporal ranges for mutations of SPEI-ITPCAS indicated that the responses of the three sub-regions (northern Shaanxi, Guanzhong and southern Shaanxi) to climate change may be quite different.

\section{Discussion}

\subsection{Meteorological data with high spatial-temporal resolution}

Validation of SPEI-OMS and SPEI-ITPCAS has proved that meteorological datasets with high spatial-temporal resolution can better reflect the characteristics of drought in regions with complex climate than OMS. Thus, comprehensive evaluations of the existing meteorological datasets in drought monitoring are necessary. Vicente-Serrano et al. (2010b) has proposed a worldwide drought index dataset based on SPEI calculated with $0.5^{\circ}$ net CDF reanalysis data. However, it is too coarse for drought monitoring at the provincial scale. ITPCAS, TRMM and CMORPH-PDF (CMORPH calibrated by probability density function matching and optimal interpolation method) are commonly used for provincial drought analysis in China (Tian and Li, 2015; Lu et al., 2018). ITPCAS has a higher spatial resolution than TRMM and a longer time range than CMORPH. Moreover, numerous studies have shown the superior performance of ITPCAS in predicting precipitation in hydrological simulations in China (Guo and Wang, 2013; He et al., 2015). Kan et al. (2013) pointed out that the accuracy of spatial distribution of precipitation data derived from ITPCAS for western China was better than those of TRMM Multi-satellite Precipitation Analysis (TMPA3B42V6) and CMORPH. In the future, we will downscale ITPCAS with auxiliary environmental factors to finer resolution so that the spatial-temporal characteristics of drought can be better identified even more precisely.

\subsection{Assessment of SPEI}

According to the algorithms of SPEI, the accuracy of SPEI depends on the following three factors: (1) accuracy of precipitation data; (2) accuracy of calculated PET; and (3) option of probability density function to fit water deficit or surplus. Precipitation from ITPCAS has been proved to be effective in modelling applications (Wang et al., 2018). Many scholars have verified that the loglogistic function, which is a probability density function and is used for calculating the SPEI, fits well the distribution of water surplus (Beguería et al., 2014; Yang et al., 2016). Therefore, the algorithms used for calculating the PET, including PM equation and Th method, need further evaluation. The error of PET calculated by Th method has been shown to be high in winter (Duan et al., 2013; Parsons et al., 2019). Figure 4d showed that in Shaanxi Province, the CDI value on the winter scale was abnormally higher than those on other seasonal and annual scales. This anomaly happened because low temperature in winter caused errors in the calculation of PET by Th method. Thus, estimates of PET in winter calculated by Th method need to be adjusted.

\subsection{Adjustments of Th method in winter}

Figures 2 and $4 \mathrm{~d}$ and Table 3 showed that drought areas in winter detected by SPEI-ITPCAS were relatively consistent with the historical drought records, while the CDI in winter was abnormal, indicating that Th method tended to overestimate the intensity of drought in winter. Tsakiris et al. (2007) proposed that the ratio of precipitation to potential evapotranspiration (briefly, P/PET) can be used as an appropriate drought index and as a way to distinguish arid and humid regions (Paulo et al., 2012). Because arid and humid regions are relatively stable, PET calculated by Th method in winter can be adjusted by $\mathrm{P} / \mathrm{PET}$ values. 


\section{Conclusions}

In this study, temperature and precipitation data were extracted from ITPCAS to calculate SPEI, and the calculation results were then validated by historical drought records. Spatial-temporal characteristics of drought on seasonal and annual scales in Shaanxi Province during the period of 1979-2016 were analyzed by SPEI-ITPCAS. Results showed that SPEI-ITPCAS was superior to SPEI-OMS in detecting drought areas of Shaanxi Province on seasonal and annual scales. The rank of drought frequency on different scales was as follows: summer $>$ spring $>$ annual $>$ autumn. The CDI values in Shaanxi Province during the period of 1979-2016 were different on seasonal and annual scales. In spring and summer, there was a general drying trend in most regions of Shaanxi Province while a significant drying trend in Weinan and Xi'an. In autumn and winter, there was a significant wetting trend in northern Shaanxi while a drying trend in other regions. Mutations of SPEI-ITPCAS occurred before the year 1990 in most regions of Shaanxi Province on different time scales.

\section{Acknowledgements}

This study was supported by the National Natural Science Foundation of China (41871307) and the Shaanxi Coordinate Innovation Plan Project of Science and Technology (2016KTCL03-17).

\section{References}

Ahmad I, Tang D S, Wang T F, et al. 2015. Precipitation trends over time using Mann-Kendall and spearman's rho tests in Swat River Basin, Pakistan. Advances in Meteorology, 2015: 431860, doi: https://doi.org/10.1155/2015/431860.

Allen K J, Ogden J, Buckley B M, et al. 2011. The potential to reconstruct broadscale climate indices associated with southeast Australian droughts from Athrotaxis species, Tasmania. Climate Dynamics, 37(9-10): 1799-1821.

Allen R, Smith M, Perrier A, et al. 1994. An update for the definition of reference evapotranspiration. ICID bulletin, 43(2): 134.

Beguería S, Vicente-Serrano S M, Reig F, et al. 2014. Standardized precipitation evapotranspiration index (SPEI) revisited: parameter fitting, evapotranspiration models, tools, datasets and drought monitoring. International Journal of Climatology, 34(10): 3001-3023.

Changnon S A, Easterling W E. 1989. Measuring drought impacts: the illinois case. Jawra Journal of the American Water Resources Association, 25(1): 27-42.

Chen Y Y, Yang K, He J, et al. 2011. Improving land surface temperature modeling for dry land of China. Journal of Geophysical Research-Atmospheres, 116(D20): 12-20.

Dai A G. 2011. Characteristics and trends in various forms of the Palmer Drought Severity Index during 1900-2008. Journal of Geophysical Research-Atmospheres, 116(D12): 1248-1256.

Duan Y, Wang W, Cai X J. 2013. Applied analyses on Palmer, SPEI and CI indices of Drought Process in Yangtze-Huaihe River Basins during Winter of 2010/Spring of 2011. Plateau Meterology, 32(4): 1126-1139. (in Chinese)

Gobena A K, Gan T Y. 2013. Assessment of trends and possible climate change impacts on summer moisture availability in western Canada based on metrics of the Palmer Drought Severity Index. Journal of Climate, 26(13): 4583-4595.

Goovaerts P. 2000. Geostatistical approaches for incorporating elevation into the spatial interpolation of rainfall. Journal of Hydrology, 228(1-2): 113-129.

Guo D L, Wang H J. 2013. Simulation of permafrost and seasonally frozen ground conditions on the Tibetan Plateau, 1981-2010. Journal of Geophysical Research-Atmospheres, 118(11): 5216-5230.

Hannaford J, Lloyd-Hughes B, Keef C, et al. 2011. Examining the large-scale spatial coherence of European drought using regional indicators of precipitation and streamflow deficit. Hydrological Processes, 25(7): 1146-1162.

He B, Lü A F, Wu J J, et al. 2011. Drought hazard assessment and spatial characteristics analysis in China. Journal of Geographical Sciences, 21(2): 235-249.

He S W, Nan Z T, Zhang L, et al. 2015. Spatial-temporal distribution of water and energy fluxes in the upper reaches of the Heihe River simulated with VIC model. Journal of Glaciology and Geocryology, 37(1): 211-225. (in Chinese)

Jia J, Wang Q, Li L H. 2016. Long-term oscillation of drought conditions in the western China: an analysis of PDSI on a decadal scale. Journal of Arid Land, 8(6): 819-831.

Jiang R G, Xie J C, He H L, et al. 2015. Use of four drought indices for evaluating drought characteristics under climate change in Shaanxi, China: 1951-2012. Natural Hazards, 75(3): 2885-2903. 
Kan B Y, Su F G, Tong K, et al. 2013. Analysis of the applicability of four precipitation datasets in the upper reaches of the Yarkant River, the Karakorum. Journal of Glaciology and Geocryology, 35(3): 710-722. (in Chinese)

Kendall M G. 1975. Rank Correlation Methods. London: Charles Griffin, 200-202.

Kim T W, Valdés J B, Aparicio J. 2002. Frequency and spatial characteristics of droughts in the Conchos River Basin, Mexico. Water International, 27(3): 420-430

Kogan F, Adamenko T, Guo W. 2013. Global and regional drought dynamics in the climate warming era. Remote Sensing Letters, 4(4): 364-372.

Liu C R, Chen H, Ning C, et al. 2018. Analysis of drought characteristics in Shaanxi Province during 1961-2016 based on SPI. Acta Agriculturae Jiangxi, 30(4): 117-122. (in Chinese)

Liu W L, Zhang M J, Wang S J, et al. 2013. Changes in precipitation extremes over Shaanxi Province, northwestern China, during 1960-2011. Quaternary International, 313-314: 118-129.

Liu Y, Yang X L, Ren L L, et al. 2015. A new physically based self-calibrating palmer drought severity index and its performance evaluation. Water Resources Management, 29(13): 4833-4847.

Liu Y F, Yuan Z H, Feng J M, et al. 2016. Dry-wet condition of Shaanxi Province in recent 56 years based on surface humidity index. Arid Land Geography, 39(6): 1186-1196. (in Chinese)

Loukas A, Vasiliades L, Tzabiras J. 2008. Climate change effects on drought severity. Advances in Geosciences, 17: 23-29.

Lu J, Jia L, Menenti M, et al. 2018. Performance of the standardized precipitation index based on the TMPA and CMORPH precipitation products for drought monitoring in China. IEEE Journal of Selected Topics in Applied Earth Observations and Remote Sensing, 11(5): 1387-1396.

Ma M W, Ren L Y, Singh V P, et al. 2015. Evaluation and application of the SPDI-JDI for droughts in Texas, USA. Journal of Hydrology, 521: 34-45.

Mann H B. 1945. Nonparametric tests against trend. Econometrico, 13(3): 245-259.

Meza F J. 2013. Recent trends and ENSO influence on droughts in Northern Chile: An application of the Standardized Precipitation Evapotranspiration Index. Weather \& Climate Extremes, 1(1): 51-58.

Naumann G, Dutra E, Barbosa P, et al. 2014. Comparison of drought indicators derived from multiple data sets over Africa. Hydrology and Earth System Sciences, 18(18): 1625-1640.

Pandey R P, Ramasastri K S. 2010. Relationship between the common climatic parameters and average drought frequency. Hydrological Processes, 15(6): 1019-1032.

Parsons D J, Rey D, Tanguy M, et al. 2019. Regional variations in the link between drought indices and reported agricultural impacts of drought. Agricultural Systems, 173: 119-129.

Paulo A A, Rosa R D, Pereira L S. 2012. Climate trends and behaviour of drought indices based on precipitation and evapotranspiration in Portugal. Natural Hazards and Earth System Sciences, 12(5): 1481-1491.

Qiao L, Cheng K, Wu L R, et al. 2012. Spatial and temporal distribution of meteorological drought disasters in Shaanxi Province over past 30 year. Bulletin of Soil and Water Conservation, 46(1): 253-256. (in Chinese)

Rhee J, Im J. 2017. Meteorological drought forecasting for ungauged areas based on machine learning: Using long-range climate forecast and remote sensing data. Agricultural and Forest Meteorology, 237-238: 105-122.

Salehnia N, Zare H, Kolsoumi S, et al. 2017a. Predictive value of Keetch-Byram Drought Index for cereal yields in a semi-arid environment. Theoretical \& Applied Climatology, 134(3-4): 1005-1014.

Salehnia N, Alizadeh A, Sanaeinejad H, et al. 2017b. Estimation of meteorological drought indices based on AgMERRA precipitation data and station-observed precipitation data. Journal of Arid Land, 9(6): 797-809.

Spinoni J, Barbosa P, de Jager A, et al. 2019. A new global database of meteorological drought events from 1951 to 2016. Journal of Hydrology: Regional Studies, 22(4): 100593-100616.

Szcześniak M, Piniewski M. 2015. Improvement of hydrological simulations by applying daily precipitation interpolation schemes in meso-scale catchments. Water, 7(2): 747-779.

Thornthwaite C W. 1937. Microclimatic studies in Oklahoma and Ohio. Science, 86(2222): 100-101.

Tian M, Li W G. 2015. Analysis of spatial and temporal characteristics of drought and flood based on TRMM remote sensing data. Transactions of the Chinese Society for Agricultural Machinery, 46(5): 252-257. (in Chinese)

Tsakiris G, Pangalou D, Vangelis H. 2007. Regional drought assessment based on the Reconnaissance Drought Index (RDI). Water Resources Management, 21(5): 821-833.

Vasiliades L, Loukas A. 2009. Hydrological response to meteorological drought using the Palmer drought indices in Thessaly, Greece. Desalination, 237(1-3): 3-21.

Vicente-Serrano S M, Beguería S, López-Moreno J I. 2010a. A multiscalar drought index sensitive to global warming: the Standardized Precipitation Evapotranspiration Index. Journal of Climate, 23(7): 1696-1718. 
Vicente-Serrano S M, Begueria S, López-Moreno J I, et al. 2010b. A new global 0.5 degrees gridded dataset (1901-2006) of a multiscalar drought index: comparison with current drought index datasets based on the Palmer Drought Severity Index. Journal of Hydrometeorology, 11(4): 1033-1043.

Vicente-Serrano S M, Beguería S, López-Moreno J I. 2011. Comment on "characteristics and trends in various forms of the Palmer Drought Severity Index (PDSI) during 1900-2008" by Aiguo Dai. Journal of Geophysical Research-Atmospheres, 116(D19): 4-13.

Wan X J, Ren Z Y, Zhang C. 2013. Research on spatial-temporal distribution of temperature and precipitation changes in Shaanxi. Journal of Arid Land Resources and Environment, 27(6): 140-147. (in Chinese)

Wang F, Wang Z M, Yang H B, et al. 2018. Study of the temporal and spatial patterns of drought in the Yellow River basin based on SPEI. Science China Earth Sciences, 61(8): 1098-1111.

Wang X Y, Zhuo L, Li C, et al. 2019. Temporal and spatial evolution trends of drought in northern Shaanxi of China: 1960-2100. Theoretical and Applied Climatology, 139(3-4): 965-979.

Wang Y D, Chen H, Liu C R, et al. 2018. Applicability of ITPCAS and CMORPH precipitation datasets over Shaanxi Province. Arid Zone Research, 35(3): 579-588. (in Chinese)

Wang Z, Guan K Y, Sheffield J, et al. 2016. Depiction of drought over sub-Saharan Africa using reanalyses precipitation data sets. Journal of Geophysical Research Atmospheres, 121(18): 10555-10574.

Wells N, Goddard S, Hayes M J. 2004. A self-calibrating Palmer Drought Severity Index. Journal of Climate, 17(12): 2335-2351.

Xue B L, Wang L, Yang K, et al. 2013. Modeling the land surface water and energy cycles of a mesoscale watershed in the central Tibetan Plateau during summer with a distributed hydrological model. Journal of Geophysical Research-Atmospheres, 118(16): 8857-8868.

Yang M J, Yan D H, Yu Y D, et al. 2016. SPEI-based spatiotemporal analysis of drought in Haihe River Basin from 1961 to 2010. Advances in Meteorology, 2016: 7658015, doi: 10.1155/2016/7658015.

Yang Q, Li M X, Zheng Z Y, et al. 2017. Regional applicability of seven meteorological drought indices in China. Science China Earth Sciences. 60(4): 745-760.

Yu F K, Huang X H, Liang Q B, et al. 2015. Ecological water demand of regional vegetation: the example of the 2010 severe drought in southwest China. Plant Biosystems-An International Journal Dealing with all Aspects of Plant Biology, 149(1): $100-110$.

Yu M X, Li Q F, Hayes M J, et al. 2014. Are droughts becoming more frequent or severe in China based on the Standardized Precipitation Evapotranspiration Index: 1951-2010? International Journal of Climatology, 34(3): 545-558.

Yuan F, Ma M W, Ren L L, et al. 2015. Possible future climate change impacts on the hydrological drought events in the Weihe River Basin, China. Advances in Meteorology, 2016: 2905198, doi: https://doi.org/10.1155/2016/2905198.

Zhai Y A. 2005. China Meteorological Disaster Canon-Shaanxi Volume. Beijing: Meteorological Press, 30-41. (in Chinese)

Zhang R, Chen Z Y, Xu L J, et al. 2019. Meteorological drought forecasting based on a statistical model with machine learning techniques in Shaanxi Province, China. Science of the Total Environment, 665: 338-346.

Zhang X S, Srinivasan R. 2009. GIS-Based spatial precipitation estimation: A comparison of geostatistical approaches. Journal of the American Water Resources Association, 45(4): 894-906. 